\title{
Effects of short-term Nordic walking training on sarcopenia-related parameters in women with low bone mass: a preliminary study
}

This article was published in the following Dove Press journal:

Clinical Interventions in Aging

30 November 2016

Number of times this article has been viewed

\author{
Zbigniew Marcin Ossowski' \\ Wojciech Skrobot ${ }^{2}$ \\ Piotr Aschenbrenner ${ }^{3}$ \\ Vida Janina Cesnaitiene ${ }^{4}$ \\ Mirosław Smaruj ${ }^{3}$ \\ 'Department of Health Promotion, \\ ${ }^{2}$ Department of Kinesiology, \\ ${ }^{3}$ Department of Physical Education, \\ Gdansk University of Physical \\ Education and Sport, Gdansk, Poland; \\ ${ }^{4}$ Department of Health, Physical and \\ Social, Lithuanian Sports University, \\ Kaunas, Lithuania
}

Background: Several studies have demonstrated the positive effects of physical activity on skeletal muscle mass and muscle strength in women with osteoporosis. However, the impact of Nordic walking training on sarcopenia-related parameters in women with low bone mass remains unknown. Therefore, the purpose of this study was to evaluate the impact of 12 weeks of Nordic walking training on skeletal muscle index, muscle strength, functional mobility, and functional performance in women with low bone mass.

Materials and methods: The participants were 45 women, aged 63-79 years, with osteopenia or osteoporosis. The subjects were randomly assigned either to an experimental group (12 weeks of Nordic walking training, three times a week) or to a control group. Skeletal muscle mass and other body composition factors were measured with octapolar bioimpedance InBody 720 analyser. Knee extensor and flexor isometric muscle strength were measured using Biodex System 4 Pro $^{\mathrm{TM}}$ dynamometers. This study also used a SAEHAN Digital Hand Dynamometer to measure handgrip muscle strength. The timed up-and-go test was used to measure functional mobility, and the 6-minute walk test was used to measure functional performance.

Results: Short-term Nordic walking training induced a significant increase in skeletal muscle mass $(P=0.007)$, skeletal muscle index $(P=0.007)$, strength index of the knee extensor $(P=0.016)$, flexor $(P<0.001)$, functional mobility $(P<0.001)$, and functional performance $(P<0.001)$ and a significant decrease in body mass $(P=0.006)$, body mass index $(P<0.001)$, and percent body fat $(P<0.001)$ in participants. Regarding handgrip muscle strength, no improvement was registered $(P=0.315)$. No significant changes in any of the analyzed parameters were observed in the control group.

Conclusion: Overall, short-term Nordic walking training induces positive changes in knee muscle strength and functional performance in women with low bone mass. This finding could be applied in clinical practice for intervention programs in women with osteopenia and osteoporosis.

Keywords: aerobic exercise, osteoporosis, muscle mass, strength, postmenopausal

\section{Introduction}

Osteoporosis and sarcopenia are common among the elderly and are associated with significant morbidity and mortality. ${ }^{1}$ Given the current secular trends in demographic groups with high longevity, the burden of both osteoporosis and sarcopenia may continue to increase.

In 2011, The International Working Group on Sarcopenia in Older People defined sarcopenia as "the age-associated loss of skeletal muscle mass and function." In 2009, the European Working Group on Sarcopenia in Older People (EWGSOP)
Correspondence: Zbigniew Marcin Ossowski

Department of Health Promotion, Gdansk University of Physical Education and Sport, ul. Kazimierza Górskiego I, 80-336 Gdańsk, Poland

$\mathrm{Tel} / \mathrm{fax}+48505 \mathrm{II} 3037$

Email zbigniew.ossowski@awf.gda.pl
Clinical Interventions in Aging 2016: | | |763-|77|

1763

Dovepress f $y$ in 0

http://dx.doi.org/10.2147/CIA.S|18995 
had already defined sarcopenia as a syndrome characterized by progressive and generalized loss of skeletal muscle mass (SM) and strength with a risk of adverse outcomes such as physical disability and poor quality of life and death. ${ }^{3}$

Importantly, sarcopenia is well known to be highly correlated with frailty and an increased risk of falling in the elderly. ${ }^{4}$ In addition to increasing the risk of falling, sarcopenia might also decrease bone strength by reducing mechanical loading on the skeleton. ${ }^{5,6}$ Sarcopenic subjects more often experience tiredness during daily activities and have lower fat mass and lean mass. ${ }^{7}$

Some studies have suggested that sarcopenia is observed in $24 \%$ and $50 \%$ of individuals aged $\geq 70$ and $<80$ years, respectively. ${ }^{8}$ Sarcopenia seems to be associated with many harmful clinical components, making this geriatric syndrome a real public health burden. ${ }^{7}$ In one American study, sarcopenia and its consequences were estimated to cost the US health care system 18 billion dollars. Sarcopenia is therefore an expensive issue for the health care system. ${ }^{9}$

It is commonly believed that physical activity can slow down the loss of SM and function. Italian researchers have recommended three types of training for sarcopenic older people: aerobic exercise, resistance exercise, and power training. ${ }^{10} \mathrm{~A}$ vast amount of literature has reviewed various training programs in which resistance and power training are engaged. ${ }^{11,12}$ However, aerobic exercise for osteopenia prevention has not received much attention. These exercises are considered vital as they are specially recommended by the American College of Sports Medicine and the American Heart Association. ${ }^{13}$

Nordic walking (NW) is one of the aerobic exercises, which has become a highly popular mode of physical activity in Central and Northern Europe. ${ }^{14} \mathrm{NW}$ is an activity oriented with specially designed poles used to push against the ground with each stride to activate the upper body while walking. The results of studies conducted in the Scandinavian countries among younger adults confirm that NW is more effective than walking without sticks. ${ }^{15} \mathrm{NW}$ provides additional benefits in upper body muscular strength ${ }^{16}$ and improvement of aerobic capacity. ${ }^{17}$ Thus, it can be considered as an important tool in the prevention of sarcopenia in older adults. Studies have also proved that practicing NW increases gait speed and cardiovascular metabolism, ${ }^{16}$ decreases systolic blood pressure in postmenopausal women, ${ }^{18}$ and reduces blood ferritin levels in elderly women. ${ }^{19}$

Additionally, the use of poles increases the stability of the body while walking. Therefore, to a certain extent, NW protects against falls, which is particularly important among those who, after undergoing trauma related to a fall, are afraid of walking.

No research has been found to prove the effect of NW training on sarcopenia-related parameters in women with reduced bone mass. Therefore, the aim of this preliminary study was to evaluate the impact of 12 weeks of NW training on skeletal muscle index (SMI), muscle strength, functional mobility, and functional performance in women with low bone mass.

\section{Materials and methods \\ Ethics}

This study was approved by the Bioethics Commission of Regional Medical Chamber according to the Declaration of Helsinki, under the process number KB-29/14. Before commencing the study, all the subjects received a verbal and written description of the experiment, and they signed an informed consent form before participation.

\section{Participants}

The study sample consisted of 45 postmenopausal women aged 63-79 years $(\mathrm{M}=68.7$ years, \pm 4.43$)$. All the participants were recruited from a group of 740 women (who agreed to the primary screening), attending various lectures at the University of the Third Age. The recruitment process is illustrated in Figure 1. The sample was randomly divided into two groups. The first group - the control group (CG) consisted of 22 women (68.32 \pm 4.06 years). Participants in the CG involved in normal daily activities appropriate to their age range. None of the subjects were engaged in an organized physical activity regimen. Women from the second group, called the experimental group (EG), participated in regular NW training (see "Training program" section) $(n=23$; $69.04 \pm 4.81$ years).

The inclusion criteria were as follows: postmenopausal female (ie, a female who had experienced her last period $>12$ months ago), nonsmoking female, diagnosed with osteopenia or osteoporosis. Low bone mass was defined by a $\mathrm{T}$-score $\leq-1 .{ }^{20}$

Subjects were excluded according to the following criteria: uncontrolled hypertension, oophorectomy, rheumatoid arthritis, pulmonary disease, and type 2 diabetes treated with insulin.

All the participants had to undergo a compulsory medical examination that revealed no contraindications to physical exercise. They were asked to provide information regarding prescribed medications as part of this study. These data 


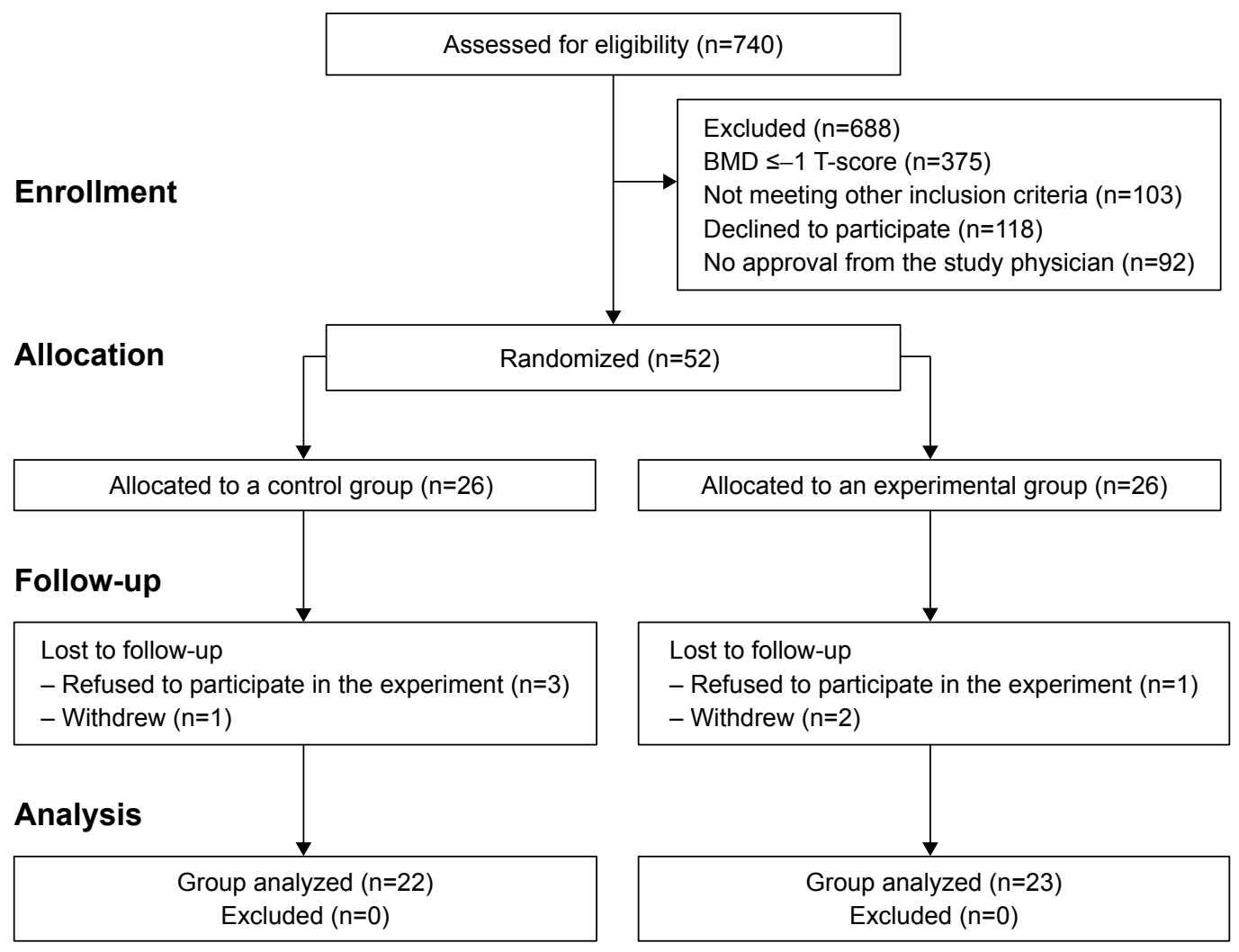

Figure I Recruitment process.

Abbreviation: BMD, bone mineral density.

included information regarding medications that may affect bone metabolism, including hormone replacement therapy, corticosteroids, and antiresorptive therapies.

A total of 17 women declared taking medicine (eight people from EG and nine from $C G$ ). Examined women were under the permanent care of a medical specialist, who monitored dosed medicines. Additionally, to limit the effects of possible variables on the study results, medicines and their doses were not altered throughout the 12-week study.

\section{Measures}

\section{Assessment of body composition and anthropometry}

Body mass (BM), SM, and percent body fat (PBF) were measured with an octapolar bioimpedance InBody 720 analyser (Biospace, Seoul, Korea) using standard protocols, with participants wearing light clothing without shoes. This technology employs eight contact electrodes: two are positioned on the palm and thumb of each hand, and the others are placed on the front part of the feet and on the heels. This device supported the study to analyze five basic body parts - left and right upper limb, trunk, and left and right lower limb - independently at frequencies of 1, 5, 50, 250, 500 , and $1,000 \mathrm{kHz}$.

The validity of bioimpedance (BIA) has been documented in several studies. In one study, no statistical difference between magnetic resonance imaging (MRI)-measured and BIA-derived values for SM was observed..$^{21}$ In other studies, BIA was used to determine skeletal muscle cutpoints for identifying elevated physical disability risk in older adults. ${ }^{22}$

EWGSOP indicates that BIA may be considered an alternative to Dual-energy X-ray absorptiometry (DXA) for determining SM and, by extension, SMI. To calculate SMI, the following formula recommended by EWGSOP was used: SM/ height ${ }^{2}$. EWGSOP defines three clinical sarcopenia conditions: 1) pre-sarcopenia, which is characterized by low muscle mass without impact on muscle strength or physical performance; 2) sarcopenia, which is characterized by low muscle mass, plus low muscle strength or low physical performance; and 3) severe sarcopenia, which is identified when all three criteria of the definition are met: low muscle mass, low muscle strength, and low physical performance. ${ }^{3}$

Body height (in $\mathrm{cm}$ ) was measured with an accuracy of $0.1 \mathrm{~cm}$. During measurement, each subject was placed 
barefoot in the orthostatic position. Body mass index (BMI) was calculated as BM/height ${ }^{2}\left(\mathrm{~kg} / \mathrm{m}^{2}\right)$.

\section{Assessment of muscle strength}

Chan et al reported that quadriceps strength and handgrip strength (HS) were independently associated with health outcomes at baseline, including quality of life, disability in daily living, hospitalization, and gait speed. ${ }^{23}$ The measurements could also aid in the identification of older adults in primary care with the poorest health outcomes.

HS was measured to estimate muscle strength and was performed with a hand dynamometer (SAEHAN Digital Hand Dynamometer, SAEHAN, Changwon, Korea). During the HS test, participants had to hold the dynamometer in their hand with the arm stretched parallel to the body while being instructed to stand upright. This measure was performed three times on the dominant hand with a rest interval of $1 \mathrm{~min}$ between measurements; finally, the best performance was used as the maximum peak (PK) of HS (in kg). The statistical analysis also included mean peak (mean PK).

Knee extensor and flexor muscle strength were measured using a Biodex System 4 Pro $^{\text {TM }}$ dynamometer (Biodex Medical Systems, Inc., Shirley, NY, USA). Data collection was performed by using a Compaq Desk Pro personal computer and Biodex software using the standard Biodex protocol. After a standardized warm-up, subjects were positioned in the equipment according to the manufacturer's manual (seated with arms hanging along the body, hands holding the lateral handles, and strap stabilization of trunk, hip, and tested thigh, with the knee flexed to $90^{\circ}$ ). For testing, the protocol reported by Symons et al with slight modifications was used. ${ }^{24}$ The isometric strength test was used for three maximal contractions, provided that one single contraction lasted $5 \mathrm{~s}$ with $30 \mathrm{~s}$ breaks. The seat position was adjusted for the leg length of each tested person. Data were analyzed using the results obtained from the dominant lower limb. The parameters of maximum peak torque (PKTQ) and mean peak torque (mean PKTQ) were analyzed for knee extension/flexion.

In this study, two recommended strength indexes were used. To calculate the first strength index, the following formula was used: PK HS/BM $(\mathrm{kg}) .{ }^{25}$ The second strength index was calculated as PKTQ knee extensor muscle strength $(\mathrm{Nm}) / \mathrm{BM}(\mathrm{kg}){ }^{26}$

\section{Assessment of functional mobility and functional performance}

The EWGSOP also recommends extending sarcopenia diagnosis with an additional component, that is, low physical performance. In this respect, the EWGSOP recommends a wide range of tests of physical performance. ${ }^{3}$ Two of these tests include the timed up-and-go (TUG) test, which has been proved to be a satisfactory measure of functional mobility in elderly persons, ${ }^{27}$ and the 6-minute walk test.

The TUG test measures the time(s) required for a subject to rise from a chair, walk $3 \mathrm{~m}$, turn around, walk back to the chair, and sit down. It has been shown to be a predictor of sarcopenia in hospitalized patients with a mean age of $70.4 \pm 7.7$ years. $^{28}$

The functional performance of the participants was assessed based on the distance covered in the 6-minute walk test. ${ }^{29}$ The experimental procedure was as follows: $5 \mathrm{~min}$ in sitting position, 6 min of continuous walking at a comfortable self-selected speed, and $5 \mathrm{~min}$ for recovery. The tests were performed on an athletic track where the temperature was $17^{\circ} \mathrm{C}$. The following instruments were used for the test: a stopwatch, measuring tape, and a Polar RS-400 heart rate monitor (Polar Electro Oy, Kempele, Finland). The 6-minute walk distance (6MWD) covered during the test was recorded in meters.

\section{Training program}

All training sessions were conducted by a certified NW coach and were held outdoors, three times a week, for $60 \mathrm{~min}$ each, over a period of 12 weeks. Participants used Nordic poles (Exel, Espoo, Finland). According to the recommendation of the International NW Federation (INWA), the pole length was determined by multiplying each subject's height in centimeter by 0.68 and rounding down to the nearest $5 \mathrm{~cm}$. During the first week of training with poles, the main goal was to improve form during the march.

Each training unit consisted of three phases. During the warm-up phase (10-13 $\mathrm{min})$, women performed isotonic exercises with poles to improve arm, leg, and torso flexibility and static and dynamic body balance.

The main part of the NW training (40 min) consisted in walking with poles over a distance of 3-4 km to reach an average heart rate between $50 \%$ and $70 \%$ of the agedependent maximal heart rate; HRmax $=206-0.88 \times$ age $^{30}$ $[($ HRmax - HRrest $) \times(0.5-0.7)]+$ HRrest. During NW, all the subjects used the diagonal-pole back condition technique recommended by INWA. ${ }^{31}$ According to the aforementioned technique, the correct usage of the poles involves a backward pole position during the loading phase, active and dynamic use of the poles, and control of the poles with the grip and strap.

Every main part of the NW training featured two short active sessions ( 2 min each). During these sessions, women performed breathing exercises and isometric exercises with an emphasis on the muscles of the lower limbs. 
The cool-down exercises (7-10 min) included dynamic and static stretching. Participants' heart rate was monitored by a Polar RS-400 heart rate monitor.

\section{Statistical analysis}

Standard statistical methods were used to calculate mean values and standard deviations (mean \pm standard deviation). The Shapiro-Wilk statistical analysis test was used to verify the normality of the data. For normally distributed results, a paired $t$-test analysis was performed to identify different results significantly. For results that were not normally distributed, a Wilcoxon signed-rank test was applied. The paired $t$-test or the Wilcoxon test was used for within-group comparisons.

The Brown-Forsyth test was used to verify the homogeneity of the variance. The between-group comparisons were performed using analysis of variance (ANOVA) tests. For homogeneous results, an ANOVA for repeated measurements and post hoc honestly significant difference Tukey test for equal sample sizes were performed to identify different results significantly. For heterogeneous results, an ANOVA Friedman's test and a right post hoc test were applied. In addition, Cohen's effect size (ES) was calculated to quantify the magnitude of statistical significance. All data were analyzed using the statistical package Statistica 10 (StatSoft, 2010), and the level of significance was $P<0.05$.

\section{Results}

Results pertaining to anthropometry, body composition, SMI, muscle strength, functional mobility, and performance in participants during the study are shown in Table 1.

This study did not indicate the presence of sarcopenia in the tested women. The SMI was $\geq 6.76 \mathrm{~kg} / \mathrm{m}^{2}$. At baseline, no statistically significant differences were observed between EG and CG with respect to the analyzed parameters.

For the within-group analysis, after the 12-week training period, $\mathrm{SMI}(\mathrm{ES}=0.22)$ and $\mathrm{SM}(\mathrm{ES}=0.18)$ showed significant increases in EG. Moreover, NW training significantly improved knee extensor and flexor muscle strength. Statistically significant increases were observed for knee extensor muscle strength for PKTQ (ES=0.37), mean PKTQ (ES=0.36), and PKTQ/BM (ES=0.47) and knee flexor muscle strength for PKTQ (ES=0.62), mean PKTQ (ES=0.65), and PKTQ/BM (ES=0.70).

After the training period, in the EG, the study also noted statistically significant increases in TUG $(\mathrm{ES}=0.79)$ and 6MWD ( $\mathrm{ES}=1.15)$ and decreases in $\mathrm{BM}(\mathrm{ES}=0.11)$, BMI $(\mathrm{ES}=0.10)$, and $\mathrm{PBF}(\mathrm{ES}=0.30)$. However, statistical tests did

Table I Results of the participant variables analyzed in this study

\begin{tabular}{|c|c|c|c|c|c|c|c|}
\hline \multirow[t]{2}{*}{ Variables } & \multicolumn{3}{|l|}{ EG } & \multicolumn{4}{|l|}{ CG } \\
\hline & Pre & Post & $P$-value & Pre & Post & $P$-value & Interaction \\
\hline \multicolumn{8}{|l|}{ Anthropometry } \\
\hline $\mathrm{BM}(\mathrm{kg})$ & $68.27 \pm 9.40$ & $67.24 \pm 9.19 *$ & $<0.001$ & $70.82 \pm 10.55$ & $70.7 I \pm 10.68$ & 0.79 & Time \\
\hline $\mathrm{BMI}\left(\mathrm{kg} / \mathrm{m}^{2}\right)$ & $26.76 \pm 3.88$ & $26.36 \pm 3.79 *$ & $<0.001$ & $27.57 \pm 3.08$ & $27.53 \pm 3.20$ & 0.82 & Time, time vs group \\
\hline \multicolumn{8}{|l|}{ Body composition } \\
\hline $\mathrm{SM}(\mathrm{kg})$ & $23.37 \pm 2.69$ & $23.86 \pm 2.83 *$ & 0.01 & $23.38 \pm 2.39$ & $23.39 \pm 2.40$ & 0.88 & Time, time vs group \\
\hline PBF (\%) & $36.03 \pm 6.62$ & $34.08 \pm 6.26 *$ & $<0.001$ & $38.02 \pm 5.72$ & $37.98 \pm 5.34$ & 0.92 & Time, time vs group \\
\hline $\mathrm{SMI}\left(\mathrm{kg} / \mathrm{m}^{2}\right)$ & $9.14 \pm 0.85$ & $9.33 \pm 0.84^{*}$ & 0.01 & $9.11 \pm 0.51$ & $9.12 \pm 0.52$ & 0.87 & Time, time vs group \\
\hline \multicolumn{8}{|c|}{ Biodex System 4 Pro ${ }^{\mathrm{TM}}$ knee extensor } \\
\hline PKTQ (Nm) & $104.05 \pm 29.00$ & II $5.60 \pm 33.30 *$ & 0.03 & $109.88 \pm 26.50$ & $104.67 \pm 22.04$ & 0.05 & Time vs group \\
\hline Mean PKTQ (Nm) & $97.97 \pm 28.79$ & $108.91 \pm 32.14 *$ & 0.02 & $104.4 \mid \pm 24.78$ & $100.33 \pm 22.41$ & 0.08 & Time vs group \\
\hline PKTQ/BM (Nm/kg) & $1.53 \pm 0.36$ & $1.72 \pm 0.44^{*, \dagger}$ & 0.02 & $1.56 \pm 0.31$ & $1.49 \pm 0.29$ & 0.12 & Time vs group \\
\hline \multicolumn{8}{|c|}{ Biodex System 4 Pro $^{\mathrm{TM}}$ knee flexor } \\
\hline PKTQ (Nm) & $41.65 \pm 14.26$ & $50.93 \pm 15.54^{*, \dagger}$ & $<0.001$ & $39.92 \pm 14.18$ & $41.30 \pm 11.09$ & 0.16 & Time, group, time vs group \\
\hline Mean PKTQ (Nm) & $38.65 \pm 13.74$ & $48.16 \pm 15.27 *,+$ & $<0.001$ & $37.04 \pm 14.09$ & $39.42 \pm 11.19$ & 0.08 & Time, group, time vs group \\
\hline PKTQ/BM (Nm/kg) & $0.62 \pm 0.20$ & $0.76 \pm 0.20^{*, \dagger}$ & $<0.001$ & $0.57 \pm 0.19$ & $0.59 \pm 0.17$ & 0.34 & Time, group, time vs group \\
\hline \multicolumn{8}{|l|}{ Hand grip } \\
\hline PK (kg) & $22.74 \pm 3.99$ & $23 . I I \pm 4.38$ & 0.44 & $22.06 \pm 3.38$ & $21.29 \pm 2.76$ & 0.27 & NS \\
\hline Mean PK (kg) & $21.48 \pm 3.93$ & $21.5 \mathrm{I} \pm 4.33$ & 0.95 & $20.16 \pm 3.24$ & $19.16 \pm 2.67$ & 0.14 & NS \\
\hline PK/BM (kg) & $0.34 \pm 0.06$ & $0.35 \pm 0.07$ & 0.11 & $0.32 \pm 0.06$ & $0.3 I \pm 0.06$ & 0.26 & NS \\
\hline TUG (s) & $5.8 I \pm 0.56$ & $5.27 \pm 0.79 *$ & $<0.001$ & $5.65 \pm 0.56$ & $5.66 \pm 0.59$ & 0.80 & Time, time vs group \\
\hline 6MWD (m) & $611.22 \pm 51.43$ & $672.96 \pm 55.5 I^{*, \dagger}$ & $<0.001$ & $608.93 \pm 79.30$ & $600.43 \pm 78.63$ & 0.23 & Time, time vs group \\
\hline
\end{tabular}

Notes: Data presented as mean \pm standard deviation; Pre, measurements at baseline; Post, measurements after 12 weeks of NW training; *significantly different from pre, $P<0.05$; ‘significantly different between groups, $P<0.05$.

Abbreviations: EG, experimental group ( $n=23)$; CG, control group ( $n=22)$; BM, body mass; BMI, body mass index; SM, skeletal muscle mass; PBF, percent body fat; SMI, skeletal muscle mass index; PKTQ, peak torque; PKTQ/BM, peak torque/body mass; PK, peak; PK/BM, peak/body mass; TUG, timed up-and-go test; 6MWD, 6-minute walk distance; NS, not significant; NW, nordic walking. 
not indicate significant changes in handgrip muscle strength among women in the EG.

In the $\mathrm{CG}$, no significant differences in the analyzed parameters were observed after 12 weeks. However, an ANOVA test showed that after 12 weeks, changes in functional performance-6MWD (ES=1.07), knee extensor muscle strength for PKTQ/BM (ES=0.62), knee flexor muscle strength for PKTQ (ES=0.71), mean PKTQ (ES=0.65), and PKTQ/BM $(\mathrm{ES}=0.92)$ - were statistically significant between the EG and the CG.

\section{Discussion}

The current study has shown that 12 -week NW training is effective in decreasing BM, BMI, and PBF and increasing SM (2.1\%) and SMI (2.08\%). Similar results were obtained by South Korean scientists who analyzed changes in body composition among three groups of elderly women (NW group, normal walking group, and CG) after practice of three times a week (60 min long) over a 12 -week study period. ${ }^{32}$ In this study, the NW and normal walking groups showed significant changes in SM $(P<0.001$ in both groups), in contrast to the results obtained for the $\mathrm{CG}$. Results also indicated significant decreases in weight $(P<0.001)$, BMI $(P=0.001)$, and PBF $(P=0.008)$ after the NW intervention. However, the normal walking group showed significant decreases in weight $(P=0.02)$ and PBF $(P=0.005)$ but not in BMI.

A recent study presented the results obtained after 8 weeks of NW training relative to normal walking training. ${ }^{33}$ The findings revealed a significantly greater improvement in SM in the elderly group. However, no evidence of a significant decrease in BM or BMI in postmenopausal women was obtained following a shorter ( 8 weeks) NW training period. ${ }^{18}$

The aforementioned results are in agreement with those reported in other studies, indicating that NW provides an advantage over general walking because it engages more muscles and results in 20\% higher calorie consumption. ${ }^{16}$

The reported data confirm that 12 weeks of NW training is effective in decreasing weight, PBF, and BMI; thus, the study is worth continuing in patients with sarcopenic obesity. Undertaking such efforts is important because, as other studies indicate, sarcopenic obesity has been associated with a greater risk of incidents of cardiovascular disease and disability than sarcopenia or obesity alone. ${ }^{34,35}$ Sarcopenic obesity has also been linked to an increased risk of falling in older adults. ${ }^{36}$

The current study additionally showed that short-term NW training is effective in improving knee muscle strength, as opposed to handgrip muscle strength, in women with osteopenia and osteoporosis.

After 3 months of walking with poles, a statistically significant improvement in knee muscle strength was observed. The greatest improvement was noted in knee flexion muscles, amounting to PKTQ (22.4\%), mean PKTQ (24.9\%), and PKTQ/BM (22.6\%). An improvement in knee extension muscle strength was also observed (PKTQ [11.2\%], mean PKTQ [11.1\%], and PKTQ/BM [12.4\%]).

Similar results were reported by Kocur et al, who studied the effect of 3 weeks (five sessions per week) of NW training and traditional walking on exercise capacity and functional fitness in patients after acute coronary syndrome. ${ }^{37}$ These studies showed improvements in lower body strength (assessed with "chair stand test") and coordination of movement and dynamic balance (in "up-and-go test") in both the training groups. Scores on the chair stand test and up-and-go test increase by $17.9 \%$ and $10.2 \%$ in the NW group and by $16.1 \%$ and $5.8 \%$ in the normal walking group, respectively. However, the results (in both tests) were significantly better for the NW group than for the normal walking group.

Parkatti et al showed that 9 weeks of walking with poles led to a moderate increase of $15 \%$ in the muscle strength of the lower extremities among the sedentary older people. ${ }^{38}$ Similarly, Eyigor et al demonstrated an increase in knee extensor muscle strength of $17 \%$ after 8 weeks of resistance training combined with walking, balance and flexibility exercises in 20 elderly women. ${ }^{39}$

A precise comparison of our results with those reported in the aforementioned studies is difficult because the authors used different training periods and tests. Certain studies also suggest that the effects of resistance training on muscle strength in older people rest entirely on neural factors in the absence of significant muscle hypertrophy. ${ }^{40}$ Certain similar adaptive mechanisms are likely to occur during NW training as well. This study shows that the increases in strength are greater than those observed for SM. These results are supported by available data demonstrating greater effects of exercise on muscle strength than on muscle mass in the elderly. ${ }^{41}$

The results of this study concerning the increase in knee muscle strength can be essential in treating sarcopenic therapy in women with low bone mass because osteoporosis associated with the postmenopausal period can negatively affect the increase in lower limb strength in physically active women. Moreover, the loss of strength in the knee extensor muscles is of particular interest because these muscles have been consistently demonstrated to be associated with physical function in daily activities such as climbing stairs, walking, and rising from a chair. ${ }^{42}$ Brech et al reported that women with postmenopausal osteoporosis presented diminished knee extensor and flexor muscle strength compared with women without postmenopausal osteoporosis. ${ }^{43}$ 
The current study did not indicate any significant effect of the 12-week NW training period on handgrip muscle strength in participants. Similar results were noted by Lee and Park, who did not register significant improvements in upper extremity muscle strength in frail people aged $\geq 70$ years. ${ }^{44}$

As NW is a walking-based exercise, it is possible that it is more effective in improving the strength of the legs than the arms. However, certain studies showed that 12 weeks of $\mathrm{NW}$ training significantly increased handgrip muscle strength (by $10.57 \%$ ) in elderly. ${ }^{30}$

The differences between the results of this study and those reported in the literature may be due to the technique used during the march. Scientists from Korea report that women use a modified technique while walking with poles, whereas our training involved full NW technique (pole back condition). The relationship between the technique used and equipment-related factors and their effect on training have also been highlighted in other studies. . $^{37,45-47}$

In the CG, there were no statistically significant changes in muscle strength among the analyzed parameters (for knee and handgrip). These findings are in agreement with those reported by other authors. ${ }^{30,34}$

It is generally known that elderly women with low bone mineral density show changes in gait,$^{48}$ greater postural imbalance, and a greater predisposition to falls. ${ }^{49}$ Therefore, exercises aimed at strengthening muscles, tai chi, and general walking are recommended to increase balance and functional mobility. The present study demonstrated that NW is effective in improving functional mobility in women with reduced bone mass. The improvement in the EG was 9.29\%, which was statistically significant.

The findings of Kocur et al suggest that a 12-week NW training program has a positive impact on selected gait parameters and may improve the postural control of women aged $>65$ years, according to the results of selected functional tests. ${ }^{50}$ Willson et al showed that using walking poles increased walking speed $(P=0.0001-0.0004)$, stride length $(P<0.0001)$, and stance time $(P<0.0001)$ relative to those measures when no poles were used. ${ }^{51}$ However, in another study, no improvement in gait parameters pertaining to walking speed was observed after a 9-week NW intervention. ${ }^{38}$

The functional mobility improvement in the participating women could also be related to an improvement in knee muscle strength under the effects of NW training. Wiacek et al showed a correlation between the strength of the lower body and postural balance in women aged 65-94 years living in long-term care facilities. ${ }^{52}$
Another study showed that a 10 -week NW program significantly improved balance, functional mobility, and aerobic endurance $(P=0.001, P=0.04$, and $P<0.0001$, respectively) in older adults aged $>60$ years. ${ }^{53}$ An improvement in functional mobility was also reported following a 12-week aerobic resistance training period in healthy older adults. ${ }^{54}$

However, Takeshima et al reported a lack of improvement in balance (measured using the Balance Master Platform System and an 8-foot up-and-go test) after 12 weeks of NW training in older adults ( 8 men and 9 women; $70 \pm 5$ years).$^{17}$ Although functional mobility improved in the NW group, it should also be noted that there was a discrepancy between the training effects indicated by previous research and the lack of a difference in balance improvement between the EG and CG. This finding prevents us from recommending NW as a superior exercise for functional mobility improvement in women with low bone mass.

The present study demonstrated that 12 weeks of NW training improved functional performance in women with low bone mass. A significant increase in the distance covered during a 6-minute walk is not surprising because previous results have suggested that NW is more effective than conventional walking in increasing oxygen consumption in healthy adults. ${ }^{16}$

Figueiredo et al demonstrated that NW training and traditional walking training improved the gait speed and endurance of the elderly. NW ES were moderate for a 6-minute walk ( $\mathrm{ES}=0.53)$ and large for gait speed $(\mathrm{ES}=0.68)$. Walking demonstrated a moderate ES for a 6-minute walk $(\mathrm{ES}=0.53)$ but a small size for gait speed $(\mathrm{ES}=0.33) .{ }^{55}$

Other scientists have observed that regular NW training (8-13 weeks) in women increases high-density lipoprotein levels and maximal oxygen uptake and reduces total cholesterol, low-density lipoprotein, and triglyceride levels. ${ }^{19,56,57}$ The results of the current study are worth highlighting because they can be essential in constructing training programs targeted at fall prevention in women with lower bone mass. Park et al reported that a decline in physical performance leads to a deterioration in the ability to cope with physical challenges on a daily basis and may increase one's fear of falling regardless of previous experience with falls. ${ }^{58}$ Moreover, in women with decreased bone mass, the loss of muscle strength may have worse clinical implications because of the relationship between reduced mobility and a possible fall and its consequences. Brech et al indicate that knee extensor or muscle strengthening through physical activity programs may be an alternative for preventing falls. ${ }^{43}$

Hence, specific physical activity programs targeting muscle strength and postural balance should be encouraged 
and should be commenced before menopause or at the onset of menopause. ${ }^{42}$

\section{Limitations}

This study was limited by various factors. First, the sample size for analysis was small owing to the number of participants who were excluded. The recruitment process aimed to minimalize the effects of variables that could impact the main purpose of the study. Thus, ultimately, only 45 of 740 women were involved in the research project. Second, the subjects who participated in this study were recruited from the University of the Third Age and voluntarily attended a health examination. Women with fragile health did not take part in this study, which might have affected the results. Third, this study did not indicate the presence of sarcopenia in the tested women. However, all the participants had low bone mass, consistent with the aim of the study. These limitations may have contributed to the underestimation of certain relationships.

\section{Conclusion}

The current study showed that 12 weeks of NW training induced significant increases in SM, SMI, knee isometric muscle strength, functional performance, and functional mobility. Moreover, NW training was effective in decreasing BM, BMI, and percent fat mass in older women with low bone mass.

The results could provide important clinical implications for therapists to pay more attention to NW training when selecting appropriate therapeutic methods, particularly in increasing knee muscle strength and functional performance in women with osteopenia and osteoporosis.

\section{Acknowledgments}

The researchers gratefully acknowledge all of the research participants. This research was funded by the Gdansk University of Physical Education and Sport within the framework of the European Union project entitled "Active lifestyles and predictors of risk for incapacity on senior population - RISINC2013". Additionally reserach was supported by National Science Centre (Poland), project no 2014/15/B/ NZ7/00976.

\section{Disclosure}

The authors report no conflicts of interest in this work.

\section{References}

1. Edwards MH, Dennison EM, Aihie Sayer A, Fielding R, Cooper C. Osteoporosis and sarcopenia in older age. Bone. 2015;80:126-130.

2. Fielding RA, Vellas B, Evans WJ, et al. Sarcopenia: an undiagnosed condition in older adults. Current consensus definition: prevalence, etiology, and consequences. International Working Group on Sarcopenia. J Am Med Dir Assoc. 2011;12:249-256.
3. Cruz-Jentoft AJ, Baeyens JP, Bauer JM, et al; European Working Group on Sarcopenia in Older People. Sarcopenia. European consensus on definition and diagnosis: report of the European Working Group on Sarcopenia in Older People. Age Ageing. 2010;39(4):412-423.

4. Topinková E. Aging, disability and frailty. Ann Nutr Metab. 2008; 52 (Suppl 1):S6-S11.

5. Rochefort GY, Pallu S, Benhamou CL. Osteocyte: the unrecognized side of bone tissue. Osteoporos Int. 2010;21(9):1457-1469.

6. Di Monaco M, Vallero F, Di Monaco R, Tappero R. Prevalence of sarcopenia and its association with osteoporosis in 313 older women following a hip fracture. Arch Gerontol Geriatr. 2011;52(1):71-74.

7. Beaudart C, Reginster JY, Petermans J, et al. Quality of life and physical components linked to sarcopenia: The SarcoPhAge study. Exp Gerontol. 2015;69:103-110.

8. Baumgartner RN, Koehler KM, Gallagher D, et al. Epidemiology of sarcopenia among the elderly in New Mexico. Am J Epidemiol. 1998; 147:755-763.

9. Janssen I, Shepard DS, Katzmarzyk PT, Roubenoff R. The healthcare costs of sarcopenia in the United States. J Am Geriatr Soc. 2004;52(1): $80-85$.

10. Iolascon G, Di Pietro G, Gimigliano F, et al. Physical exercise and sarcopenia in older people: position paper of the Italian Society of Orthopaedics and Medicine (OrtoMed). Clin Cases Miner Bone Metab. 2014;11(3):215-221.

11. Peterson MD, Sen A, Gordon PM. Influence of resistance exercise on lean body mass in aging adults: a meta-analysis. Med Sci Sports Exerc. 2011;43(2):249-258.

12. Puthoff ML, Nielsen DH. Relationships among impairments in lower extremity strength and power, functional limitations, and disability in older adults. Phys Ther. 2007;87(10):1334-1347.

13. Nelson ME, Rejeski WJ, Blair SN, et al. Physical activity and public health in older adults. Recommendation from the American College of Sports Medicine and the American Heart Association. Circulation. 2007; 116:1094-1105.

14. Turk Z, Vidensek S, Micetic Turk D. Nordic walking: a new form of physical activity in the elderly. Acta Med Croatica. 2007;61 (Suppl 1): S33-S36.

15. Tschentscher M, Niederseer D, Niebauer J. Health benefits of Nordic walking: a systematic review. Am J Prev Med. 2013;44(1): 76-84.

16. Church TS, Earnest CP, Morss GM. Field testing of physiological responses associated with Nordic walking. Res Q Exerc Sport. 2002;73(3): 296-300.

17. Takeshima N, Islam MM, Rogers ME, et al. Effects of Nordic walking compared to conventional walking and band-based resistance exercise on fitness in older adults. J Sports Sci Med. 2013;12(3):422-430.

18. Latosik E, Zubrzycki IZ, Ossowski Z, et al. Physiological responses associated with Nordic-walking training in systolic hypertensive postmenopausal women. J Hum Kinet. 2014;43:185-190.

19. Kortas J, Prusik K, Flis D, et al. Effect of Nordic walking training on iron metabolism in elderly women. Clin Interv Aging. 2015;10: 1889-1896.

20. Czerwinski E, Badurski JE, Marcinowska-Suchowierska E, Osieleniec J. Current understanding of osteoporosis according to the position of the World Health Organization (WHO) and International Osteoporosis Foundation. Ortop Traumatol Rehabil. 2007;9:337-356.

21. Chien MY, Huang TY, Wu YT. Prevalence of sarcopenia estimated using a bioelectrical impedance analysis prediction equation in communitydwelling elderly people in Taiwan. J Am Geriatr Soc. 2008;56: $1710-1715$.

22. Janssen I, Baumgartner RN, Ross R, Rosenberg IH, Roubenoff R. Skeletal muscle cutpoints associated with elevated physical disability risk in older men and women. Am J Epidemiol. 2004;159: 413-421.

23. Chan OY, van Houwelingen AH, Gussekloo J, Blom JW, den Elzen WP. Comparison of quadriceps strength and handgrip strength in their association with health outcomes in older adults in primary care. Age (Dordr). 2014;36(5):9714. 
24. Symons TB, Vandervoort AA, Rice CL, Overend TJ, Marsh GD. Reliability of a single-session isokinetic and isometric strength measurement protocol in older men. J Gerontol A Biol Sci Med Sci. 2005; 60(1):114-119.

25. Dong R, Wang X, Guo Q, et al. Clinical relevance of different handgrip strength indexes and mobility limitation in the elderly adults. J Gerontol A Biol Sci Med Sci. 2016;71(1):96-102.

26. Choquette S, Bouchard DR, Doyon CY, Sénéchal M, Brochu M, Dionne IJ. Relative strength as a determinant of mobility in elders 67-84 years of age, a nuage study: nutrition as a determinant of successful aging. J Nutr Health Aging. 2010;14(3):190-195.

27. Podsiadlo D, Richardson S. The timed "Up \& Go": a test of basic functional mobility for frail elderly persons. J Am Geriatr Soc. 1991;39(2): $142-148$.

28. Martinez BP, Gomes IB, Oliveira CS, et al. Accuracy of the timed up and go test for predicting sarcopenia in elderly hospitalized patients. Clinics (Sao Paulo). 2015;70(5):369-372.

29. American Thoracic Society Statement. Guidelines for the six-minute walk test. Am J Respir Crit Care Med. 2002;166:111-117.

30. Gulati M, Shaw LJ, Thisted RA, Black HR, Bairey Merz CN, Arnsdorf MF. Heart rate response to exercise stress testing in asymptomatic women: the St. James women take heart project. Circulation. 2010;122:130-137.

31. International Nordic Walking Association. INWA Instructor Manual. 3rd ed. Helsinki: Suomen Latu; 2005.

32. Song MS, Yoo YK, Choi CH, Kim NC. Effects of Nordic walking on body composition, muscle strength, and lipid profile in elderly women. Asian Nurs Res. 2013;7(1):1-7.

33. Park SD, Yu SH. The effects of Nordic and general walking on depression disorder patients' depression, sleep, and body composition. J Phys Ther Sci. 2015;27(8):2481-2485.

34. Zamboni M, Mazzali G, Fantin F, Rossi A, Di Francesco V. Sarcopenic obesity: a new category of obesity in the elderly. Nutr Metab Cardiovasc Dis. 2008;18:388-395.

35. Stephen WC, Janssen I. Sarcopenic-obesity and cardiovascular disease risk in the elderly. J Nutr Health Aging. 2009;13(5):460-466.

36. Kim JH, Choi SH, Lim S, et al. Sarcopenia and obesity: gender-different relationship with functional limitation in older persons. $J$ Korean Med Sci. 2013;28:1041-1047.

37. Kocur P, Deskur-Smielecka E, Wilk M, Dylewicz P. Effects of Nordic walking training on exercise capacity and fitness in men participating in early, short-term inpatient cardiac rehabilitation after an acute coronary syndrome - a controlled trial. Clin Rehabil. 2009;23(11):995-1004.

38. Parkatti T, Perttunen J, Wacker P. Improvements in functional capacity from Nordic walking: a randomized-controlled trial among elderly people. J Aging Phys Act. 2012;20(1):93-105.

39. Eyigor S, Karapolat H, Durmaz B. Effects of a group-base exercise program on the physical performance, muscle strength and quality of life in older women. Arch Gerontol Geriatr. 2007;45:259-271.

40. Flanigan KM, Giuseppe L, Griffin JK, Ralph W. Age related biology and disease of muscle and nerve. Neurol Clin. 1998;16:659-668.

41. Frontera WR, Meredith CN, O'Reilly KP, Knuttgen HG, Evans WJ. Strength conditioning in older men: skeletal muscle hypertrophy and improved function. Am Physiol Soc. 1988;64:1038-1043.

42. Henwood TR, Riek S, Taaffe DR. Strength versus muscle power-specific resistance training in community-dwelling older adults. $J$ Gerontol A Biol Sci Med Sci. 2008;63(1):83-91.
43. Brech GC, Alonso AC, Luna NM, Greve JM. Correlation of postural balance and knee muscle strength in the sit-to-stand test among women with and without postmenopausal osteoporosis. Osteoporos Int. 2013;24(7): 2007-2013.

44. Lee HS, Park JH. Effects of Nordic walking on physical functions and depression in frail people aged 70 years and above. JPhys Ther Sci. 2015; 27(8):2453-2456

45. Figard-Fabre H, Fabre N, Leonardi A, Schena F. Physiological and perceptual responses to Nordic walking in obese middle-aged women in comparison with the normal walk. Eur J Appl Physiol. 2010;108(6):1141-1151.

46. Hansen EA, Smith G. Energy expenditure and comfort during Nordic walking with different pole lengths. J Strength Cond Res. 2009;23: 1187-1194.

47. Dziuba AK, Żurek G, Garrard I, Wierzbicka-Damska I. Biomechanical parameters in lower limbs during natural walking and Nordic walking at different speeds. Acta Bioeng Biomech. 2015;17:95-101.

48. ElDeeb AM, Khodair AS. Three-dimensional analysis of gait in postmenopausal women with low bone mineral density. $J$ Neuroeng Rehabil. 2014;11:55.

49. Silva RB, Costa-Paiva L, Morais SS, Mezzalira R, Ferreira ND, Pinto-Neto AM. Predictors of falls in women with and without osteoporosis. J Orthop Sports Phys Ther. 2010;40(9):582-588.

50. Kocur P, Wiernicka M, Wilski M, et al. Does Nordic walking improves the postural control and gait parameters of women between the age 65 and 74: a randomized trial. $J$ Phys Ther Sci. 2015;27(12):3733-3737.

51. Willson J, Torry MR, Decker MJ, Kernozek T, Steadman JR. Effects of walking poles on lower extremity gait mechanics. Med Sci Sports Exerc. 2001;33(1):142-147.

52. Wiacek M, Hagner W, Hagner-Derengowska M, et al. Correlations between postural stability and strength of lower body extremities of women population living in long-term care facilities. Arch Gerontol Geriatr. 2009;48(3):346-349.

53. Virág A, Karóczi CK, Jakab A, Vass Z, Kovács E, Gondos T. Short-term and long-term effects of Nordic walking training on balance, functional mobility, muscle strength and aerobic endurance among Hungarian community-living older people: a feasibility study. J Sports Med Phys Fitness. 2014;55(11):1285-1292.

54. Desjardins-Crépeau L, Berryman N, Fraser SA, et al. Effects of combined physical and cognitive training on fitness and neuropsychological outcomes in healthy older adults. Clin Interv Aging. 2016;11: $1287-1299$.

55. Figueiredo S, Finch L, Mai J, Ahmed S, Huang A, Mayo NE. Nordic walking for geriatric rehabilitation: a randomized pilot trial. Disabil Rehabil. 2013;35(12):968-975.

56. Hagner W, Hagner-Derengowska M, Wiacek M, Zubrzycki IZ. Changes in level of $\mathrm{VO}_{2}$ max, blood lipids and waist circumference in the response to moderate endurance training as a function of ovarian aging. Menopause. 2009;16(5):1009-1013.

57. Kukkonen-Harjula K, Hiilloskorpi H, Mänttäri A, et al. Self-guided brisk walking training with or without poles: a randomized-controlled trial in middle-aged woman. Scand J Med Sci Sports. 2007;17(14):316-323.

58. Park JH, Cho H, Shin JH, et al. Relationship among fear of falling, physical performance, and physical characteristics of the rural elderly. Am J Phys Med Rehabil. 2014;93:379-386.
CAS, Scopus and the Elsevier Bibliographic databases. The manuscript management system is completely online and includes a very quick and fair peer-review system, which is all easy to use. Visit http://www.dovepress. com/testimonials.php to read real quotes from published authors.
Clinical Interventions in Aging

\section{Publish your work in this journal}

Clinical Interventions in Aging is an international, peer-reviewed journa focusing on evidence-based reports on the value or lack thereof of treatments intended to prevent or delay the onset of maladaptive correlates of aging in human beings. This journal is indexed on PubMed Central, MedLine,

\section{Dovepress}

Submit your manuscript here: http://www.dovepress.com/clinical-interventions-in-aging-journal 